\title{
Warm and cool thresholds as a function of rate of stimulus temperature change
}

\author{
DAN R. KENSHALO AND CHARLES E. HOLMES, ${ }^{2}$ FLORIDA STATE UNIVERSITY \\ PAUL B. WOOD, ${ }^{3}$ CENTRAL WESLEYAN COLLEGE
}

The variables which are said to affect human temperature sensitivity are the skin temperature, the area of thermal stimulation and the rate at which the temperature of the skin is changed. Of these, the last has been only partially described. Measurements of the warm and cool thresholds were made on two males, experienced in making threshold judgments, when the rate of stimulus temperature change was varied between $0.01^{\circ}-0.3^{\circ} \mathrm{C} / \mathrm{sec}$. Both the warm and cool thresholds remained constant at rates of $0.1^{\circ} \mathrm{C} / \mathrm{sec}$ and above but increased rapidly when slower rates were used. The effect of slow rates of stimulus temperature change was greater on the warm threshold than upon the cool threshold. It is concluded that the rate of temperature change does not represent information about the rate constants of stimulation of warm and cool receptors but that its effect is by way of the rate at which thermal adaptation occurs.

Hensel (1950) has listed three variables of thermal stimulation which affect the sensitivity of human subjects to warm and cool stimuli. These are the temperature to which the skin has been adapted, the area of skin over which the thermal energy is applied, and the rate at which the temperature of the skin is changed. The first variable, adapted skin temperature, resulted in a large warm and small cool thresholds when the skin had been adapted to low temperatures $\left(29^{\circ} \mathrm{C}\right.$ and lower). When the skin had been adapted to high temperatures $\left(37^{\circ} \mathrm{C}\right.$ and higher) the warm thresholds were small but the cool thresholds were large (Hensel, 1950; Kenshalo, Nafe, \& Brooks, 1961).

The second variable, area of stimulation, is inversely related to the intensity of thermal stimulation required to produce threshold warm (Hardy \& Oppel, 1937; Kenshalo, Decker, \& Hamilton, 1967) and cool (Hardy \& Oppel, 1938) sensations.

The third variable of human temperature sensitivity, the rate at which the temperature of the skin is changed, is the subject of this investigation. It has received relatively little attention. The facts that are available appear contradictory. When conducted thermal energy was applied to an area of $20 \mathrm{~cm}^{2}$ on the volar surface of the forearm, Hensel (1950) found that he could change the skin temperature from $29^{\circ} \mathrm{C}$ to $36^{\circ} \mathrm{C}$ at rates of $0.007^{\circ} \mathrm{C} / \mathrm{sec}$ or less without producing a thermal sensation. When the rate of temperature change was systematically varied, and starting from normal skin temperature (about $33.5^{\circ} \mathrm{C}$ ), he found that the warm threshold remained relatively constant at rates of warming of $0.015^{\circ} \mathrm{C} / \mathrm{sec}$ and higher. When slower rates of warming were used the warm threshold increased markedly. It is difficult to determine from his data what happened to the cool threshold when various rates of cooling were used, except that at slow rates of cooling, the cool threshold seemed to increase.

Non-penetrating radiant energy seems to produce threshold warm sensations at far smaller rates of skin temperature change than those required by conducted thermal energy. Threshold warm sensations have been reported when the rate of increase of skin temperature was only $0.003^{\circ} \mathrm{C} / \mathrm{sec}$ for a 3 sec exposure (Hardy \& Oppel, 1937; Hendler \& Hardy, 1960). Cool threshold sensations (produced by exposure to a block of dry ice) occurred when the rate of skin cooling was approximately $0.004^{\circ} \mathrm{C} /$ sec for a 1 sec exposure (Hardy \& Oppel, 1938). For both warm and cool stimulation the area of exposure was larger than $200 \mathrm{~cm}^{2}$. When smaller areas were exposed, the rate of skin temperature change required to produce a threshold sensation increased. When the area exposed was limited to $23.8 \mathrm{~cm}^{2}$ of the forehead, the rate of skin temperature change required to produce a threshold warm sensation was $+0.017^{\circ} \mathrm{C} / \mathrm{sec}$ for $3 \mathrm{sec}$, and $-0.007^{\circ} \mathrm{C} /$ sec for 1 sec was required to produce a threshold cool sensation. These data tell us very little about the rate of skin temperature change as a variable of the thermal threshold except to indicate that a confounding influence may be the area of the skin surface over which the temperature change was applied.

The purpose of this investigation is to extend and complete the observations of Hensel (1950) in describing the dependence of warm and cool threshold sensations upon the rate of change of the stimulus temperature when the skin of the forearm is maintained at its normal temperature.

\section{Subjects}

\section{METHOD}

The Ss were three male undergraduates 19, 22 , and 27 years of age. Each $S$ had a minimum of $30 \mathrm{~h}$ of practice in making threshold thermal discriminations. The site of stimulation was an area on the dorsal surface of the forearm approximately $3 \mathrm{~cm}$ below the bend of the elbow. The hair was shaved from the site at least $10 \mathrm{~h}$ before-each experimental 
session. The Ss were instructed to abstain from eating or smoking for $1 \mathrm{~h}$ prior to each experimental session.

\section{Apparatus}

The chair in which the $S$ sat was in a climate controlled chamber $6.5 \times 9.0 \times 6.5 \mathrm{~m}$. The temperature of the chamber was maintained at $230.15^{\circ} \mathrm{C}$ and $20 \%$ humidity. The stimulating apparatus was similar to that described by Kenshalo (1963). The stimulator operated on the Peltier principle and was constructed of a series of junctions of two dissimilar conducting metals, bismuth telluride and copper. When a direct current was passed through the junctions of these metals in one direction, the stimulating surface warmed while the opposite surface cooled. When the polarity of the current was reversed, the stimulating surface cooled while the opposite surface warmed. The rate of warming or cooling of the stimulating surface depended upon, and could be regulated by, the amount of current delivered to the stimulator.

The temperature of the stimulating surface was monitored by a copper Constantan thermocouple which was located on the stimulator surface and came in direct contact with the skin. The thermocouple also provided a feedback to the current control circuits so that the temperature of the stimulator could be maintained within $0.012^{\circ} \mathrm{C}$ of the desired temperature. Changes in the temperature of the stimulator of as little as $0.05^{\circ} \mathrm{C}$ could be presented to the $\mathrm{S}$ at rates of up to $2^{\circ} \mathrm{C} / \mathrm{sec}$. The stimulator had a surface area of $14.44 \mathrm{~cm}^{2}$ and rested on the skin with a pressure of $10.5 \mathrm{~g} / \mathrm{cm}^{2}$.

\section{Procedure}

The $\mathbf{S}$ was seated in an adjustable chair and was allowed to adapt to the chair and the temperature of the chamber for a period of $10 \mathrm{~min}$. Following this, the skin temperature of the shaved area on the dorsal forearm was measured by a copper Constantan thermocouple soldered to a $12.5 \times 11.0$ $x \quad 0.1 \mathrm{~mm}$ silver plate. The current control apparatus was set to maintain the stimulator at skin temperature and it was then placed on the arm. A second $10 \mathrm{~min}$ adaptation period permitted the $S$ to adapt to the pressure of the stimulator.

In order to measure the effect of the rate of change of the stimulus temperature upon the warm and cool thresholds, the stimulus control apparatus was set so that various intensities of warming or cooling could be produced at a rate of $0.3^{\circ}, 0.1^{\circ}$, $0.05^{\circ}, 0.02^{\circ}$, or $0.01^{\circ} \mathrm{C} / \mathrm{sec}$ during a measurement session.

At the termination of the second 10 min adaptation period, thermal stimuli were presented to the $\mathrm{S}$. The temperature of the stimulator was maintained at skin temperature for $55 \mathrm{sec}$ between stimulations. The duration of each intensity of thermal stimulation was maintained for $10 \mathrm{sec}$ regardless of the rate of temperature change used to achieve that intensity. For example, if the stimulus presentation sequence called for a warm stimulus change of $1.0^{\circ} \mathrm{C}$ at a rate of $0.01^{\circ} \mathrm{C} / \mathrm{sec}$ them, starting from a skin temperature of $3.15^{\circ} \mathrm{C}$, the stimulator temperature began to rise at a rate of $0.01^{\circ} \mathrm{C} / \mathrm{sec}$. One hundred seconds later, the temperature of the stimulator reached $32.5^{\circ} \mathrm{C}$. It was maintained at that temperature for $10 \mathrm{sec}$ and then its temperature was rapidly returned to $31.5^{\circ} \mathrm{C}$. After $55 \mathrm{sec}$ at $31.5^{\circ} \mathrm{C}$, the next stimulus intensity was presented.

Each threshold measurement session consisted of three ascending and three descending series of the method of limits at one of the five rates of temperature change. The mean of the temperatures midway between those for which the $S$ gave two consecutive reports for "cool" or "warm," and "no change" constituted the threshold for the session. Measurements of the warm and cool thresholds using each of the five rates of temperature change were repeated three times on each $\mathrm{S}$, making a total of 18 measurements of each threshold on each $S$ at each rate of temperature change.

\section{RESULTS}

The mean warm and cool thresholds, starting from normal skin temperature (approximately $31.5^{\circ} \mathrm{C}$ ) for each of the three $S s$ and using the several rates of stimulus temperature change, are shown in Fig. 1. There was very little effect of rate of stimulus change of $0.1^{\circ} \mathrm{C} / \mathrm{sec}$ and faster upon either the warm or the cool thresholds. When the rate of temperature change was $0.05^{\circ} \mathrm{C} / \mathrm{sec}$, the warm threshold increased for two of the three $\mathrm{Ss}$, but an increase in the cool threshold occurred for only one of the three Ss. Slower lower rates of change resulted in marked increases in both the warm and the cool thresholds, although the warm thresholds seemed to be affected more by slower rates of change than the cool thresholds.

\section{Discussion}

We are unable to confirm the lack of an effect of slow rates of warming $\left(>0.015^{\circ} \mathrm{C} / \mathrm{sec}\right)$ upon the warm threshold reported by Hensel (1950). Nor is there anything in our data to suggest that a warm threshold of $+0.009^{\circ} \mathrm{C}$ at a rate of warming of $0.003^{\circ} \mathrm{C} / \mathrm{sec}$ might be achieved, as reported by Hardy and Oppel (1937). The cool thresholds were less affected by slow rates of cooling than were the warm thresholds. But the rate of cooling at which the first effect upon the cool threshold can be seen in our data $\left(0.05^{\circ} \mathrm{C} / \mathrm{sec}\right)$ is at least an order of magnitude larger than that reported $\left(0.004^{\circ} \mathrm{C} / \mathrm{sec}\right)$ by Hardy and Oppel (1938) to achieve a cool threshold of about $-0.004^{\circ} \mathrm{C}$. We cannot account for these differences 


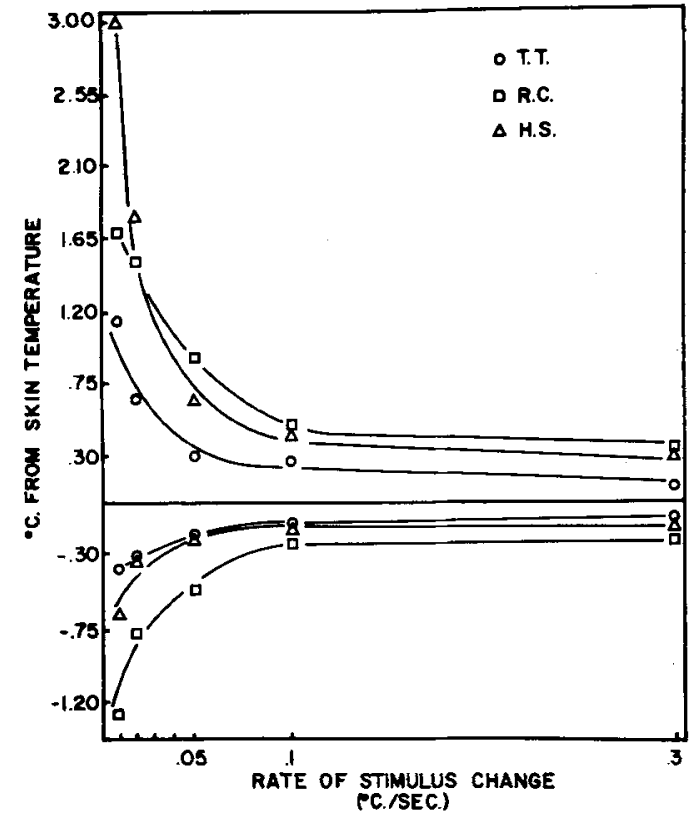

Fig. 1. The effect of the rate of the stimulus temperature change upon the warm and cool thresholds of three male subjects measured at normal skin temperature. The ordinate shows the change from normal skin temperature necessary to produce threshold warm and cool sensations at each of the rates of change in temperature. Rates of change as low as $0.1^{\circ} \mathrm{C} / \mathrm{sec}$ failed to increase either threshold. Rates of temperature change slower than $0.1^{\circ} \mathrm{C} / \mathrm{sec}$ resulted in increases in both warm and cool thresholds although its effect was more pronounced upon the warm threshold.

except to suggest that differences in the site of stimulation and the area over which the stimulation was applied may be important parameters. The difference in the method of stimulation (radiant versus conducted energy) employed by Hardy and Oppel, and in this and Hensel's studies is not a likely contributing factor since Kenshalo, Decker, and Hamilton (1967) have shown that similar warm thresholds can be obtained using the two methods of warming the skin.

Small rates of temperature change apparently have a much greater effect upon the warm threshold than upon the cool threshold. This may be interpreted in at least two different ways. The first is more traditional and assumes separate receptors which have different rate constants of response for sensing warm and cool stimuli. Another explanation of these data is also possible. It does not require the assumption of separate receptor systems to mediate warm and cool sensations, but assumes that the increase in threshold with slow rates of stimulus temperature change is related to the temporal course of thermal adaptation. According to Kenshalo and Scott (1966), adaptation to warm and cool stimuli, starting from normal skin temperature, was rapid at first and, within the first minute, slowed markedly. The increase in both the warm and cool thresholds at slow rates of temperature change may be accounted for by the fact that initially adaptation occurred at a more rapid rate than that at which the stimulus temperature changed. As the stimulus temperature change continued in time, the rate of adaptation slowed so that eventually the rate of temperature change exceeded the rate of adaptation and a threshold sensation was produced. As shown by their data, the temporal course of adaptation to warm stimuli was more rapid during the first minute than it was to cool stimuli. Therefore, it would be expected that slow rates of temperature change would have a greater effect upon the warm thresholds than upon the cool thresholds.

It seems probable that if adaptation were started from a high skin temperature-e.g., $35^{\circ} \mathrm{C}$-the initial rate of adaptation to warmer temperatures will be slower than to cooler temperatures. The converse of this should also be true; were adaptation started from low skin temperatures-e.g., $30^{\circ} \mathrm{C}$-the initial rate of adaptation to warmer temperatures should be faster than it is to cooler temperatures. If these expectations are correct, then the apparent differential effect of rate of the stimulus temperature change upon the warm and cool thresholds depends upon the temperature at which the skin has been maintained during the measurements and does not reflect the effects of a different rate constant for warm receptors than for cool receptors.

If the adaptation hypothesis is correct, then the rate of stimulus temperature change is not an independent variable but is merely a reflection of the state of adaptation of whatever receptor mechanism(s) is responsible for sensing warm and cool stimuli. Also derived from this explanation would be the expectation that at skin temperatures above that to which complete adaptation (complete disappearance of a thermal sensation) can occur, the warm threshold would be at a minimum and independent of the rate of stimulus temperature change. Likewise, when the skin has been adapted to temperatures below that to which complete thermal adaptation can occur, the cool threshold should be independent of the rate of the stimulus temperature change.

\section{References}

Hardy, J. D., \& Oppel, T. W. Studies in temperature sensation III. The sensitivity of the body to heat and spatial summation of the end-organ responses, J. Clin. Investig., 1937, 16, 533-540. Hardy, J. D., \& Oppel, T. W. Studies in temperature sensation IV. The stimulation of cold by radiation. J. Clin. Investig., 1938, 17, $771-777$

Hendler, E., \& Hardy, J. D. Infrared and microwave effects on skin heating and temperature sensation. IRE Transact. Med. Electron., 1960, ME-7, 143-152.

Hensel, H. Temperaturempfindung und intracutane Warmebewegung. Pflüger's Arch. ges. Physiol., 1950, 252, 165-215.

Kenshalo, D. R. Improved method for the psychophysical study of the temperature sense, Rev. Scient. Instrum., 1963, 34, 8, $883-886$. 
Kenshalo, D. R., Decker, T., \& Hamilton, Anne. Comparisons of spatial summation on the forehead, forearm, and back produced by radiant and conducted heat. J. comp. physiol. Psychol., $1967,63,510-515$.

Kenshalo, D. R., Nafe, J. P., \& Brooks, Barbara. Variations in thermal sensitivity. Science, 1961, 134, 104-105.

Kenshalo, D. R., \& Scott, H. H., Jr. Temporal course of thermal adeptation. Science, 1966, 151, 1095-1096.

\section{Hotes}

1. Supported by NSF Grant GB-2473 and USPHS Grant NB-02992.

2. Now at University of South Carolina, Columbia.

3. This research was conducted while on leave from Central Wesleyan College. Central. South Carolina, and participating in NSF Grant No. GE-7585

(Accepted for publication September 13, 1967.) 